\title{
Efeito da densidade de estocagem na homogeneidade do crescimento de juvenis de pirarucu em ambiente confinado(1)
}

\author{
Bruno Adan Sagratzki Cavero(2), Manoel Pereira-Filho(2), Rodrigo Roubach(2), Daniel Rabello Ituassú(2), \\ André Lima Gandra ${ }^{(2)}$ e Roger Crescêncio(3)
}

\begin{abstract}
Resumo - O objetivo deste trabalho foi avaliar o efeito da densidade de estocagem sobre a homogeneidade do crescimento de juvenis de pirarucu (Arapaima gigas) em tanques-rede de pequeno volume. Foram usados 12 tanques-rede de $1 \mathrm{~m}^{3}$ em um viveiro de $120 \mathrm{~m}^{2}$ perfazendo três tratamentos $(15,20$ e 25 peixes $/ \mathrm{m}^{3}$ ) com quatro repetições. Os peixes foram estocados com peso médio inicial de $10,1 \pm 0,3 \mathrm{~g}$ e distribuídos homogeneamente $(p>0,05)$ entre os tratamentos. Os coeficientes de variação do crescimento e do fator de condição não apresentaram diferenças significativas $(p>0,05)$ ao contrário do consumo e da conversão alimentar aparente $(\mathrm{p}<0,05)$. O consumo foi inversamente proporcional ao incremento da densidade, indicando que o aumento da densidade de estocagem favoreceu o melhor aproveitamento do alimento. Não foram observadas diferenças comportamentais entre os tratamentos. O crescimento dos juvenis de pirarucu não é influenciado pela densidade de estocagem ou por interações intra-específicas.
\end{abstract}

Termos para indexação: Arapaima gigas, manejo de pesca, piscicultura.

\section{Stocking density effect on growth homogeneity of juvenile pirarucu in confined environments}

\begin{abstract}
The objective of this work was to evaluate the stocking density over fish growth homogeneity of pirarucu (Arapaima gigas) juveniles in small volumes cages. Twelve $1 \mathrm{~m}^{3}$ net-cages were used in a $120 \mathrm{~m}^{2}$ earth pond consisting of three treatments $\left(15,20\right.$ and $\left.25 \mathrm{fish} / \mathrm{m}^{3}\right)$ with four repetitions each. Fish were stocked with an initial mean weight of $10.1 \pm 0.3 \mathrm{~g}$ and homogeneous distributed $(\mathrm{p}>0.05)$ between treatments. Coefficient of variation for growth and condition factor did not present significant $(p>0.05)$ differences, contrary to consumption and apparent feed conversion $(\mathrm{p}<0.05)$. Consumption was inversely proportional to the increment of density, indicating that stockings densities increases are favorable to a better feed use. There were not any observed behavior differences between treatments. Juveniles pirarucu growth was not influenced by the stocking density or intra-specifics interactions.
\end{abstract}

Index terms: Arapaima gigas, fishery management, fish culture.

\section{Introdução}

O pirarucu (Arapaima gigas), peixe da família Osteoglossidae (Nelson, 1994; Li \& Wilson, 1996), é provavelmente a espécie mais promissora para o de-

(1) Aceito para publicação em 20 de setembro de 2002.

Extraído da dissertação de mestrado apresentada pelo primeiro autor ao Instituto Nacional de Pesquisas da Amazônia (Inpa)/Universidade Federal do Amazonas, Manaus, AM.

(2) Inpa, Coordenação de Pesquisas em Aquacultura, Caixa Postal 478, Petrópolis, CEP 69083-000 Manaus, AM. E-mail: basc@inpa.gov.br, pmanoel@inpa.gov.br, roubach@inpa.gov.br, dituassu@inpa.gov.br, agandra@inpa.gov.br

(3) Embrapa-Centro de Pesquisa Agroflorestal do Acre, Caixa Postal 321, CEP 69908-970 Rio Branco, AC. E-mail: roger@cpafac.embrapa.br senvolvimento da criação de peixes em regime intensivo na região Amazônica. Possui alta velocidade de crescimento, podendo alcançar até $10 \mathrm{~kg}$ no primeiro ano de criação (Carvalho \& Nascimento, 1992; Imbiriba, 2001), grande rusticidade ao manuseio e respiração aérea (Fontenele, 1953,1955), condição que pode facilitar sua criação em tanques-rede de pequeno volume, além de não manifestar canibalismo quando confinado em altas densidades (Cavero, 2002) e de ser facilmente treinado para aceitar alimentação com ração extrusada (Crescêncio, 2001). No entanto, o conhecimento sobre o comportamento e crescimento do pirarucu, em qualquer modalidade de criação intensiva, ainda é escasso.

A homogeneidade no crescimento dos peixes, em ambientes confinados, é consequiência de diversos fatores que influenciam o desempenho dessa popula- 
ção. Criações em tanques-rede de pequeno volume podem ser mais vantajosas que as criações tradicionais, uma vez que permitem altas densidades de estocagem e, quando ideais, podem quebrar o status social de dominância e subordinação (Alanärä \& Brännäs, 1996), tendendo à manutenção de lotes mais homogêneos (Trzebiatowski et al., 1981; Teskeredzic et al., 1986) e, conseqüentemente, aumentando a produtividade (Hengsawat et al., 1997). A estocagem de lotes de peixes com tamanhos homogêneos iniciais influenciam na homogeneidade do lote final (Stefansson et al., 2000).

Densidades inadequadas de estocagem de peixes podem trazer complicações para a criação. MacLean \& Metcalfe (2001) observaram, na criação do salmão do Atlântico, que baixas densidades de estocagem influenciaram o aparecimento de classes hierárquicas, dominantes e subordinadas, em que os dominantes monopolizam as zonas de alimentação e o alimento, diferenciando o crescimento entre essas duas classes. Densidades de estocagem excessivas também podem causar variações no crescimento dos peixes, afetando a homogeneidade dos lotes, principalmente quando o adensamento de peixes é grande, dificultando com isso o acesso ao alimento (Schimittou, 1993) e gerando competição nas zonas de alimentação (Huntingford \& Leaniz, 1997). Embora os fenômenos que geram estresse e a variação do crescimento nos peixes nem sempre estejam relacionados à tomada de alimento, existem aqueles que influenciam na condição fisiológica e sanidade dos peixes como o déficit de oxigênio, no caso de peixes de respiração aquática obrigatória (Ono \& Kubitza, 1999), e o ataque de agentes patogênicos (Pavanelli et al., 1998).

A adoção da técnica de tanques-rede tem se difundido mundialmente (Castagnolli \& Torrieri-Junior, 1980) e apresenta algumas vantagens, como seu uso em ambientes de difícil acesso, onde a construção de represas e viveiros escavados é inviável, além das condições de manejo que permitem seu uso em escala comercial e familiar.

O objetivo deste trabalho foi avaliar o efeito da densidade de estocagem sobre a variação do crescimento de juvenis de pirarucu em tanques-rede de pequeno volume.

\section{Material e Métodos}

$\mathrm{O}$ experimento foi realizado nas dependências da Coordenação de Pesquisas em Aquacultura (CPAQ), do Instituto Nacional de Pesquisas da Amazônia (Inpa), no período de 9 de maio a 22 de junho de 2002. Os animais, juvenis de pirarucu, eram oriundos do rio Madre de Dios, Bolívia, importados por firma de Rio Branco, AC, para onde eram inicialmente transportados de barco e estocados até a sua comercialização. Os peixes foram remetidos a Manaus, AM, por via aérea.

Foram utilizados 12 tanques-rede, com aproximadamente $1 \mathrm{~m}^{3}$ cada, e neles foram distribuídas três densidades $\left(15,20\right.$ e 25 peixes $\left./ \mathrm{m}^{3}\right)$, perfazendo três tratamentos com quatro repetições em um delineamento inteiramente casualizado. O experimento durou 45 dias e os animais foram alimentados até a saciedade aparente, três vezes ao dia ( $7 \mathrm{~h}, 11 \mathrm{~h}$ e $17 \mathrm{~h})$, todos os dias. Foi utilizada ração extrusada comercial, específica para peixes carnívoros, com $45 \%$ de proteína e energia bruta de $3.000 \mathrm{kcal} / \mathrm{kg}$.

Os tanques-rede, flutuantes, foram colocados em um viveiro de $120 \mathrm{~m}^{3}(8 \times 15 \times 1 \mathrm{~m})$ com renovação diária de água (durante seis horas e vazão de $100 \mathrm{~L}$ de água/minuto), protegidos com tela sombrite com a finalidade de evitar a predação por aves e a incidência dos raios solares de uma forma direta, já que quando jovens, os olhos dos pirarucus são sensíveis às radiações solares (Sanchez, 1960). Os juvenis de pirarucu foram estocados homogeneamente ( $>0,05)$ nas unidades experimentais, com peso médio inicial de $10,1 \pm 0,36 \mathrm{~g}$. Os dados de peso (g) e comprimento $(\mathrm{cm})$, de cada uma das unidades experimentais, ao final do experimento, foram usados para calcular os seguintes parâmetros de desempenho dos peixes: Ganho de peso (GP) = peso final - peso inicial; consumo individual médio de ração no final do experimento $(\mathrm{CIMFi})=\Sigma$ consumo médio diário (por tanque-rede); conversão alimentar aparente $(\mathrm{CAA})=\mathrm{CIMFi} /($ Peso médio final - Peso médio inicial); fator de condição $(\mathrm{K})=$ peso final/comprimento final; coeficiente de variação do peso dos peixes $(\mathrm{CVP}, \%)=$ 100 (desvPm/peso médio final); coeficiente de variação do comprimento dos peixes $(\mathrm{CVC}, \%)=100(\operatorname{desvCm} / \mathrm{com}$ primento médio final); coeficiente de variação do fator de condição $(\mathrm{CVK}, \%)=100$ (desvK/K médio final).

A influência ambiental sobre o desempenho dos peixes foi verificada a cada quatro dias a partir das observações de parâmetros físico-químicos da água como amônia total $\left(\mathrm{NH}_{3}+\mathrm{NH}_{4}{ }^{+}\right)$em $\mathrm{mg} / \mathrm{L}$, condutividade elétrica $\left(\mu \mathrm{S} / \mathrm{cm}^{2}\right)$, nitrito $\left(\mathrm{NO}_{2}^{-}\right)$em $\mathrm{mg} / \mathrm{L}$, oxigênio dissolvido em $\mathrm{mg} / \mathrm{L}, \mathrm{pH}$, temperatura $\left({ }^{\circ} \mathrm{C}\right)$ e transparência $(\mathrm{cm})$. 
As observações comportamentais sobre a ocorrência de agressões, competição por alimento e canibalismo, foram realizadas visualmente durante o período de cada alimentação.

Para garantir a homogeneidade dos peixes no início do experimento, estes foram pesados (g) e a seguir os dados foram analisados através do teste $\mathrm{F}$ a $5 \%$ de probabilidade (Ayres et al., 2000). Os dados da biometria final dos tratamentos foram submetidos à análise de variância e as médias comparadas pelo teste de Tukey a 5\% de probabilidade (Mendes, 1999).

\section{Resultados e Discussão}

As concentrações da amônia total $\left(\mathrm{NH}_{3}+\mathrm{NH}_{4}{ }^{+}\right)$ e do nitrito $\left(\mathrm{NO}_{2}{ }^{-}\right)$, e as medidas de temperatura, oxigênio dissolvido, $\mathrm{pH}$ e condutividade na água do viveiro, não influenciaram no desempenho dos peixes e parecem estar dentro daquelas toleradas pela espécie (Tabela 1). Essas oscilações estão dentro das aceitáveis para a criação de peixes em tanques-rede (Schmittou, 1993).

Os valores do peso inicial e final, do comprimento total inicial e final (Tabela 2) e do ganho de peso (Tabe-

Tabela 1. Valores médios dos parâmetros de qualidade da água, durante o período experimental de 45 dias (amostragens a cada quatro dias), da criação de juvenis de pirarucu (Arapaima gigas) em tanques-rede de pequeno volume.

\begin{tabular}{lcc}
\hline $\begin{array}{l}\text { Parâmetros ambientais } \\
\text { monitorados }\end{array}$ & Média \pm desvio-padrão & Variação \\
\hline Potencial hidrogeniônico $(\mathrm{pH})$ & $7,2 \pm 1,8$ & $5,0-9,8$ \\
Temperatura $\left({ }^{\circ} \mathrm{C}\right)$ & $28,4 \pm 1,45$ & $24,5-29,8$ \\
Condutividade $\left(\mu \mathrm{S} / \mathrm{cm}^{-2}\right)$ & $40,0 \pm 5,2$ & $31,0-46,0$ \\
Transparência $(\mathrm{cm})$ & $64,1 \pm 27,3$ & $29,0-100$ \\
Nitrito $\left(\mathrm{NO}_{2}^{-}\right)(\mathrm{mg} / \mathrm{L})$ & $0,0 \pm 0,0$ & 0 \\
Amônia total $\left(\mathrm{NH}_{3}+\mathrm{NH}_{4}{ }^{+}\right)(\mathrm{mg} / \mathrm{L})$ & $0,5 \pm 0,0$ & 0 \\
Oxigênio dissolvido $\left(\mathrm{mg}^{-\mathrm{L}}\right)$ & $6,0 \pm 1,5$ & $3,8-8,2$ \\
\hline
\end{tabular}

Tabela 2. Médias do peso inicial, do peso final, do comprimento total inicial (CTI) e do comprimento total final (CTF) de juvenis de pirarucu (Arapaima gigas) criados em tanques-rede de pequeno volume em três densidades de estocagem (peixes $/ \mathrm{m}^{3}$ ) durante 45 dias $^{(1)}$.

\begin{tabular}{ccccc}
\hline Peixes $/ \mathrm{m}^{3}$ & Peso inicial $(\mathrm{g})$ & Peso final $(\mathrm{g})$ & $\mathrm{CTI}(\mathrm{cm})$ & $\mathrm{CTF}(\mathrm{cm})$ \\
\hline 15 & $9,84 \pm 0,06 \mathrm{a}$ & $104,57 \pm 9,1 \mathrm{a}$ & $12,02 \pm 1,12 \mathrm{a}$ & $24,25 \mathrm{a}$ \\
20 & $10,11 \pm 0,32 \mathrm{a}$ & $100,62 \pm 10,2 \mathrm{a}$ & $11,67 \pm 0,93 \mathrm{a}$ & $23,75 \mathrm{a}$ \\
25 & $10,4 \pm 0,61 \mathrm{a}$ & $107,72 \pm 11,9 \mathrm{a}$ & $12,23 \pm 1,06 \mathrm{a}$ & $24,29 \mathrm{a}$ \\
\hline \multicolumn{5}{c}{ (1)Médias seguidas da mesma letra, na coluna, não diferem entre si pelo } \\
teste de Tukey a 5\% de probabilidade; os valores das variáveis são apre- \\
sentados como média \pm desvio-padrão.
\end{tabular}

la 3) não apresentaram diferenças significativas entre os tratamentos $(p>0,05)$, refletindo nas distribuições das amplitudes de variação do peso e comprimento médio dos peixes entre os tratamentos. Esses resultados podem ser visualizados pelos coeficientes de variação de peso (CVP) e comprimento (CVC) dos peixes, os quais também não apresentaram diferença significativa entre os tratamentos ( $>00,05)$ (Tabela 3 ).

Carneiro (1997) também constatou falta de correlação entre os coeficientes de variação de peso e comprimento, com as densidades de estocagem, em tilápias vermelhas da Flórida (Oreochromis mossambicus x $O$. niloticus) em tanques-rede. Já Watanabe et al. (1990) e Suresh \& Lin (1992) constataram que tilápias vermelhas, quando criadas em tanques-rede, apresentam maior heterogeneidade do que aquelas criadas em viveiros convencionais.

Os resultados de Watanabe et al. (1990) e Suresh \& Lin (1992) provavelmente foram influenciados pela demanda de oxigênio dentro dos tanques-rede com o aumento da densidade, uma vez que as espécies citadas nesses trabalhos possuem respiração aquática, ao contrário do pirarucu, que possui respiração aérea obrigatória e obtém a maior parte do oxigênio através da bexiga natatória (Brauner \& Val, 1996).

$O$ fator de condição $(K)$ não apresentou diferença significativa entre os tratamentos ( $p>0,05)$ (Tabela 4). Entretanto, os coeficientes de variação do fator de condição (CVK) apresentaram diferenças significativas entre os tratamentos $(\mathrm{p}<0,05)$. A variação encontrada no CVK foi mínima, corroborando os resultados de CVP e CVC, indicando que o crescimento em todos os tratamentos foi semelhante com relação a esses parâmetros (Tabelas 3 e 4).

Os resultados do fator de condição $(\mathrm{K})$ revelam que a condição dos peixes em todos os tratamentos

Tabela 3. Médias do ganho de peso (g), dos coeficientes de variação do peso (CVP) e do comprimento (CVC) de juvenis de pirarucu (Arapaima gigas) criados em tanques-rede de pequeno volume em três densidades de estocagem (peixes $/ \mathrm{m}^{3}$ ) durante 45 dias $^{(1)}$.

\begin{tabular}{cccc}
\hline Peixes $/ \mathrm{m}^{3}$ & Ganho de peso & CVP & CVC \\
\hline 15 & $104,57 \pm 9,1 \mathrm{a}$ & $21,15 \pm 3,16 \mathrm{a}$ & $7,21 \pm 0,97 \mathrm{a}$ \\
20 & $100,62 \pm 10,2 \mathrm{a}$ & $23,66 \pm 7,01 \mathrm{a}$ & $7,60 \pm 2,36 \mathrm{a}$ \\
25 & $107,72 \pm 11,9 \mathrm{a}$ & $22,87 \pm 5,69 \mathrm{a}$ & $6,94 \pm 0,57 \mathrm{a}$ \\
\hline \multicolumn{4}{l}{ Médias seguidas da mesma letra, na coluna, não diferem entre si pelo } \\
teste de Tukey a 5\% de probabilidade; os valores das variáveis são apre- \\
sentados como média \pm desvio-padrão.
\end{tabular}

Pesq. agropec. bras., Brasília, v. 38, n. 1, p. 103-107, jan. 2003 
foi a mesma, enquanto o consumo de alimento foi inversamente proporcional à densidade de estocagem (Tabela 4). Esses resultados indicam que a melhor distribuição do alimento, evitando perdas, e a otimização do consumo não estão relacionadas com a condição dos peixes e sim com o número de juvenis de pirarucu $/ \mathrm{m}^{3}$. Com a melhor distribuição do alimento, os lotes são mais homogêneos (Trzebiatowski et al., 1981; Teskeredzic et al., 1986), aumentam a produtividade (Hengsawat et al., 1997) e melhoram a conversão alimentar aparente (Tabela 4).

Peixes que apresentam comportamento gregário, como o salmão do Atlântico, podem ser influenciados por condições que favoreçam o aparecimento de classes hierárquicas, como densidades de estocagem inadequadas. Nessas condições, os dominantes monopolizam o alimento e o consomem primeiro (MacLean \& Metcalfe, 2001), assim como pode ocorrer a formação de zonas de alimentação, as quais são defendidas pelos peixes dominantes, impedindo que os peixes subordinados se alimentem e, com isso, aumentam a heterogeneidade do lote de criação (Huntingford \& Leaniz, 1997). Apesar de os juvenis de pirarucu apresentarem comportamento gregário, não foi observado o estabelecimento de classes hierárquicas nem a formação de zonas específicas de alimentação dentro dos tanques-rede, em nenhuma das densidades de estocagem. Provavelmente isto ocorre porque tanques-rede de pequeno volume $\left(1 \mathrm{~m}^{3}\right)$ não possibilitam a criação de zonas específicas de alimentação (Cavero, 2002).

A quebra da dominância por densidades de estocagem adequadas, relacionadas por Alanärä \& Brännäs (1996), contribui para a manutenção de lotes menos heterogêneos (Trzebiatowski et al., 1981;

Tabela 4. Médias dos coeficientes do fator de condição $(\mathrm{K})$, de sua variação (CVK), dos valores do consumo individual médio de ração (CIMFi) e da conversão alimentar aparente (CAA) de juvenis de pirarucu (Arapaima gigas) criados em tanques-rede de pequeno volume em três densidades de estocagem (peixes $/ \mathrm{m}^{3}$ ) durante 45 dias $^{(1)}$.

\begin{tabular}{|c|c|c|c|c|}
\hline Peixes $/ \mathrm{m}^{3}$ & $\mathrm{~K}$ & CVK & CIMFi & $\mathrm{CAA}$ \\
\hline 15 & $4,86 \pm 0,37 \mathrm{a}$ & $5,95 \pm 0,35 b$ & $116,11 \pm 11,9 \mathrm{a}$ & $1,12 \pm 0,10 \mathrm{a}$ \\
\hline 20 & $4,66 \pm 0,32 \mathrm{a}$ & $6,94 \pm 0,50 \mathrm{a}$ & $98,83 \pm 12,5 \mathrm{ab}$ & $0,99 \pm 0,20 \mathrm{ab}$ \\
\hline 25 & $4,71 \pm 0,27 \mathrm{a}$ & $7,58 \pm 0,59 \mathrm{a}$ & $86,7 \pm 10,8 \mathrm{~b}$ & $0,80 \pm 0,06 \mathrm{~b}$ \\
\hline
\end{tabular}

Pesq. agropec. bras., Brasília, v. 38, n. 1, p. 103-107, jan. 2003
Teskeredzic et al., 1986), aumenta a produtividade (Hengsawat et al., 1997), melhora o acesso ao alimento (Schimittou, 1993), gera menor competição por alimento nas zonas de alimentação (Huntingford \& Leaniz, 1997) e diminui a agressividade e o canibalismo entre os peixes (Lahti \& Lower, 2000).

No decorrer do período experimental, não foram registrados casos de agressão, competição por alimento ou canibalismo entre os juvenis de pirarucu, que pudessem dar suporte a inferências de que a variação do peso e do comprimento entre os tratamentos esteja relacionada às relações comportamentais intra-específicas da espécie e às densidades de estocagem.

\section{Conclusão}

As densidades de estocagem não influenciam a variação do crescimento de juvenis de pirarucu.

\section{Agradecimentos}

Ao Conselho Nacional de Desenvolvimento Científico e Tecnológico (CNPq) e à Agencia Española de Cooperación Internacional (AECI) - Projeto Pirarucu, pelo suporte financeiro.

\section{Referências}

ALANÄRÄ, A.; BRÄNNÄS, E. Dominance in demandfeeding behavior in Arctic char and rainbow trout: the effect of stocking density. Journal of Fish Biology, London, v. 48 , n. 2, p. 242-254, 1996.

AYRES, M.; AYRES, M. J.; AYRES, D. L.; SANTOS, A. S. Bio stat 2.0: aplicações estatísticas nas áreas biológicas e médicas. Belém: Sociedade Civil Mamirauá/CNPq, 2000. 272 p.

BRAUNER, C. J.; VAL, A. L. The interaction between $\mathrm{O}_{2}$ and $\mathrm{CO}_{2}$ exchange in the obligate air breather, Arapaima gigas, and the facultative air breather, Lipossarcus pardalis. In: VAL, A. L.; ALMEIDA-VAL, V. M. F.; RANDALL, D. J. Physiology and biochemistry of the fishes of the Amazon. Manaus: Instituto Nacional de Pesquisas da Amazônia, 1996. p. 101-110.

CARNEIRO, P. C. F. Produção de tilápias vermelhas da Flórida em tanques-rede em represa rural. 1997. 75 f. Dissertação (Mestrado em Aqüicultura) - Universidade Estadual Paulista, Jaboticabal, 1997. 
CARVALHO, L. O. D. M.; NASCIMENTO, C. N. B. do. Engorda de pirarucus (Arapaima gigas) em associação com búfalos e suínos. Belém: Embrapa-CPATU, 1992. 21 p. (Circular Técnica, 65).

CASTAGNOLLI, N.; TORRIERI-JUNIOR, O. Confinamento de peixes em tanques-rede. Ciência e Cultura, São Paulo, v. 32, n. 11, p. 1513-1517, nov. 1980.

CAVERO, B. A. S. Densidade de estocagem de juvenis de pirarucu, Arapaima gigas (Cuvier, 1829) em tanques-rede de pequeno volume. $2002.51 \mathrm{f}$. Dissertação (Mestrado em Biologia de Água Doce e Pesca Interior) Instituto Nacional de Pesquisas da Amazônia, Fundação Universidade do Amazonas, Manaus, 2002.

CRESCÊNCIO, R. Treinamento alimentar de alevinos de pirarucu, Arapaima gigas (Cuvier, 1829), utilizando atrativos alimentares. 2001. 35 f. Dissertação (Mestrado em Biologia de Água Doce e Pesca Interior) Instituto Nacional de Pesquisas da Amazônia, Fundação Universidade do Amazonas, Manaus, 2001.

FONTENELE, O. Contribuição ao conhecimento do pirarucu Arapaima gigas (Cuvier) em cativeiro (Actinopiterygii, Osteoglossidae). Fortaleza: Departamento Nacional de Obras Contra as Secas, 1955. p. 235 250. (Publicação, 166).

FONTENELE, O. Hábitos de desova do pirarucu Arapaima gigas (Cuvier) (PISCES: Isospondyli, Arapaimidae), e evolução da sua larva. Fortaleza: Departamento Nacional de Obras Contra as Secas, 1953. 22 p. (Publicação, 153).

HENGSAWAT, K.; WARD, F. J.; JARURATJAMORN, $\mathrm{P}$. The effect of stocking density on yield, growth and mortality of African catfish (Clarias gariepinus Burchell 1822) cultured in cages. Aquaculture, Amsterdam, v. 152, p. 67-76, 1997.

HUNTINGFORD, F. A.; LEANIZ, C. G. de. Social dominance, prior residence and acquisition of profitable feeding sites in juvenile Atlantic salmon. Journal of Fish Biology, London, v. 51, n. 5, p. 1009-1014, 1997.

IMBIRIBA, E. P. Potencial da criação de pirarucu, Arapaima gigas, em cativeiro. Acta Amazonica, Manaus, v. 31, n. 2, p. 299-316, 2001.

LAHTI, K.; LOWER, N. Effects of size asymmetry on aggression and food acquisition in Arctic char. Journal of Fish Biology, London, v. 56, n. 4, p. 915-922, 2000.

LI, G. Q.; WILSON, M. V. H. Phylogeny of Osteoglossomorpha. In: STIASSNY, M. L.; PARENTI, L. R.; JOHNSON, G. D. (Ed.). Interrelations of fishes. San Diego: Academic, 1996. p. 163-174.
MacLEAN, A.; METCALFE, N. B. Social status, access to food, and compensatory growth in the juvenile Atlantic salmon. Journal of Fish Biology, London, v. 58, n. 5, p. 1331-1346, 2001.

MENDES, P. P. Estatística aplicada à aqüicultura. Recife: Bagaço, 1999. 265 p.

NELSON, J. S. Fishes of the world. 3rd ed. New York: J. Wiley, 1994. 600 p.

ONO, E. A.; KUBITZA, F. Cultivo de peixes em tanques-rede. 2. ed. rev. ampliada. Jundiaí: F. Kubitza, 1999. $68 \mathrm{p}$.

PAVANELLI, G. C.; EIRAS, J. C.; TAKEMOTO, R. M. Doenças de peixes: profilaxia, diagnóstico e tratamento. Maringá: Ed. da Universidade Estadual de Maringá/CNPq, 1998. $264 \mathrm{p}$

SANCHEZ, J. R. El paiche: gigante del Amazonas. Lima: Instituto del Mar del Perú, 1960. 16 p.

SCHIMITTOU, H. R. Produção de peixes em alta densidade em tanques-rede de pequeno volume. Campinas: Associação Americana de Soja/Mogiana Alimentos, 1993. $78 \mathrm{p}$.

STEFANSSON, M. O.; IMSLAND, A. K.; JENSSEN, M. D.; JONASSEN, T. M.; STEFANSSON, S. O.; FITZGERALD, R. The effect of different initial size distributions on the growth of Atlantic halibut. Journal of Fish Biology, London, v. 56, n. 4, p. 826-836, 2000.

SURESH, A. V.; LIN, C. K. Effect of stocking density on water quality and production of red tilapia in recirculated system. Aquaculture Engineering, Oxford, v. 11, p. 122,1992

TESKEREDZIC, E.; TESKEREDZIC, Z.; MALNAR, Z.; HACMANJEK, M.; MARGUS, D. The effect of stocking density on growth and mortality of rainbow trout cultured in floating cages in the brackish water of the river Krka Estuary. Acta Biologica Iugoslavica, Serija E: Ichthyologia, Belgrade, v. 18, n. 1, p. 41-46, 1986.

TRZEBIATOWSKI, R.; FILIPIAK, J.; JAKUBOWSKI, R. Effect of stocking density on growth and survival of rainbow trout (Salmo gairdneri Rich). Aquaculture, Amsterdam, v. 22, p. 289-295, 1981.

WATANABE, W. O.; CLARK, J. H.; DUNHAM, J. B.; WICKLUND, R. I.; OLLA, B. L. Culture of Florida red tilapia in marine cages: the effect of stocking density and dietary protein on growth. Aquaculture, Amsterdam, v. 90 p. 123-124, 1990 